\title{
Pengaruh Suhu dan Konsentrasi Katalis Pada Proses Esterifikasi Distilat Asam Lemak Minyak Sawit (DALMs) Menjadi Biodiesel
}

\author{
Rismawati Rasyid \\ Jurusan Teknik Kimia, Universitas Muslim Indonesia, Makassar
}

\begin{abstract}
Abstrak
Pembuatan biodiesel dari minyak kelapa sawit sudah populer dibanding distilat asam lemak minyak sawit (DALMs). Minyak kelapa sawit mentah atau Crude Palm Oil (CPO) dalam proses pemurniannya menjadi minyak goring, menghasilkan produk samping berupa Distilat asam lemak minyak sawit (DALMs) dari proses distilasi. Proses esterifikasi DALMs menghasilkan senyawa ester atau biodiesel menggunakan pereaksi metanol dengan katalisator asam klorida $(\mathrm{HCl})$. Reaksi dijalankan pada reaktor batch pada tekanan diatas satu atmosfer dengan variasi suhu dan konsentrasi katalis. Proses dijalankan dengan putaran pengaduk $600 \mathrm{rpm}$, perbandingan ekivalen metanol dengan DALMs 1,4 kali stokiometri merupakan variabel tetap pada tekanan 6,5 atm. Didapatkan bahwa hubungan konstanta kecepatan reaksi dengan suhu menghasilkan $k=28921$ Exp $(-5241 / T)$ dan variasi konsentrasi katalis dengan $\mathrm{k}=0,0039 \operatorname{Exp}\left(0,336 \mathrm{C}_{\mathrm{kat}}\right)$, menghasilkan konversi sebesar $77 \%$. Kondisi optimal diperoleh pada suhu $383 \mathrm{~K}$ dengan konsentrasi katalis $6 \%$ dari berat DALMs.
\end{abstract}

Kata kunci : Biodiesel, DALMs, esterifikasi

\begin{abstract}
Biodiesel production from palm oil is more popular than Free Fatty Acid Distilat (FFAD). In its purification by distilation process to be seasoning oil, Crude Palm Oil (CPO) produces FFAD as a byproduct. By using methanol as reactant and $\mathrm{HCl}$ as a catalyst an esterification process of FFAD produces ester compound at biodiesel. In this experiment the applied present was done at higherthis 1 atm and the temperature and catalyst concentration was varied in batch reactor. The was held at a constant reactions of $600 \mathrm{rpm}$ and constant pressure of $6,5 \mathrm{~atm}$, in which the ratio stoichiometry of 1.4 times was higher is methanol as compared FFAD. It was found that correlation of reaction rate constant with temperature is $\mathrm{k}=28921 \mathrm{Exp}(-5241 / \mathrm{T}) \mathrm{ml} / \mathrm{mgrek} / \mathrm{menit}$, while the correlation of reaction rate constant with catalyst concentration is $\mathrm{k}=0,0039 \operatorname{Exp}\left(0,336 \mathrm{C}_{\mathrm{kat}}\right) \mathrm{ml} / \mathrm{mgrek} / \mathrm{minute}$. The reaction convertions of $77 \%$ was also found. The optimal condition was obtained at $383 \mathrm{~K}$ with $6 \%$ catalyst concentration of FFAD weight.
\end{abstract}

Keywords: Biodiesel, FFAD, esterification

\section{PENDAHULUAN}

Bahan bakar minyak dunia yang bersumber dari fosil saat ini mulai semakin menipis cadangannya, sehingga diperlukan suatu bahan bakar alternatif yang dapat menjadi penunjang kebutuhan tersebut. Sementara dampak lain yang ditimbulkan akibat pemakaian bahan bakar fosil adalah pencemaran lingkungan merupakan dampak negatif dan perlu mendapat perhatian khusus pula. Salah satu sumber bahan bakar yang mampu menjadi solusi dari masalah tersebut adalah biodiesel (Darnoko and Cheriyan, 2000).

Keunggulan kelapa sawit yang diolah menjadi biodisel sebagai pengganti fungsi minyak bumi untuk bahan bakar menjadi solusi bagi masalah pencemaran lingkungan. Gas buang yang di hasilkan termasuk bahan biodegradability dengan emisi polutan yang rendah, kadar hidrokarbon yang terbakar dan gas $\mathrm{CO}$ yang dihasilkan lebih kecil serta bebas $\mathrm{SO}_{2}$ (Noureddini, $\mathrm{H}$, and Zhu, D, 1997). 
Kelapa sawit dapat menghasilkan Crude Palm Oil (CPO) 23-26\% dari berat tandan segar. DALMs sebagai hasil samping pemurnian CPO selama ini belum terlalu optimal dimanfaatkan. Penggunaan DALMs sebagai bahan baku pembuatan biodiesel sangat potensial, hal ini di dukung oleh besarnya produksi minyak sawit .

Kekentalan minyak nabati relatif lebih tinggi dibanding minyak bumi, karena rantai karbon dalam asam lemak yang di hasilkan lebih panjang (Bailey,A, 1945). Salah satu cara untuk mengurangi masalah ini melalui proses esterifikasi dengan alkohol, misalnya metanol atau etanol.

DALMs pada suhu reaksi dapat larut dalam alkohol, sehingga model reaksi yang terjadi adalah reaksi pseudo homogen. Neraca massa komponen asam lemak pada reaksi esterifikasi dengan metanol dilakukan pada reactor batch (Fogler,1999) :

Rate of input - Rate of output - Rate of reaction $=$ Rate of accumulation

$$
0-0-\left(-\mathrm{r}_{\mathrm{A}}\right) \mathrm{V}=-\frac{d N_{A}}{d t}
$$

Sehingga persamaan (3) menjadi :

$$
\left(\mathrm{r}_{\mathrm{A}}\right) \mathrm{V}=-\frac{d N_{A}}{d t}
$$

Persamaan (4) dengan asumsi orde reaksi dua sehingga diperoleh :

$$
\mathrm{k} \mathrm{C}_{\mathrm{A}}^{2}=-\frac{d N_{A}}{V d t}
$$

Jumlah ekivalen A setiap waktu sama dengan jumlah ekivalen A mula-mula dikurangi dengan ekivalen A yang bereaksi, maka :

$$
\mathrm{N}_{\mathrm{A}}=\mathrm{N}_{\mathrm{A} 0}-\mathrm{N}_{\mathrm{A} 0} \mathrm{X}_{\mathrm{A}}
$$

Dimana :

$$
\begin{aligned}
& \mathrm{C}_{\mathrm{A}}=\frac{N_{A}}{V}=\frac{N_{A 0}\left(1-X_{A}\right)}{V} \\
& \text { atau : } \\
& \mathrm{C}_{\mathrm{A}}=\mathrm{C}_{\mathrm{A} 0}\left(1-\mathrm{X}_{\mathrm{A}}\right)
\end{aligned}
$$

Jika persamaan diatas di substitusi menghasilkan persamaan berikut :
Proses esterifikasi antara asam lemak dan alkohol akan menghasilkan senyawa ester dan air dengan persamaan umum:

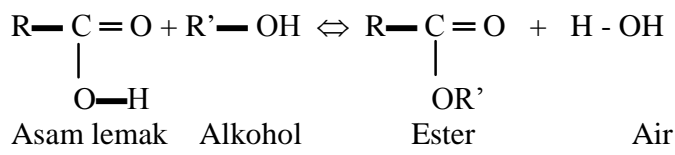

Reaksi esterifikasi pada persamaan (1) dapat disederhanakan menjadi :

$$
\begin{aligned}
& \mathrm{A}+\mathrm{B} \rightleftarrows \mathrm{C}+\mathrm{D} \\
& \frac{-d C_{A 0}\left(1-X_{A}\right)}{d t}=\mathrm{k} \mathrm{C}_{\mathrm{A} 0}{ }^{2}\left(1-\mathrm{X}_{\mathrm{A}}\right)^{2}(9)
\end{aligned}
$$

Sehingga persamaan (9) menjadi :

$$
\frac{d X_{A}}{d t}=\mathrm{k} \mathrm{C}_{\mathrm{A} 0}\left(1-\mathrm{X}_{\mathrm{A}}\right)^{2}
$$

Nilai kecepatan reaksi ( $\mathrm{k}$ ) dengan batas : $\mathrm{X}_{\mathrm{A}}=0$ pada $\mathrm{t}=\mathrm{t}_{0}$, dan $\mathrm{X}_{\mathrm{A}}=\mathrm{X}_{\mathrm{A}}$ pada $\mathrm{t}=$ $\mathrm{t}$, persamaan (10) diselesaikan dengan metode Rungge Kutta untuk mendapatkan nilai konstanta kecepatan reaksi dan kesesuaian hasil yang diperoleh dicek dengan menggunakan Golden Section.

\section{METODE PENELITIAN}

Pada penelitian ini variabel konstan yakni kecepatan pengadukan $600 \mathrm{rpm}$, perbandingan pereaksi $1: 1,4$ stokiometri antara DALMs dengan metanol dan dilakukan pada tekanan 6,5 atm. Variasi suhu yang ditinjau setiap kenaikan $10{ }^{\circ} \mathrm{C}$, mulai dari $80^{\circ} \mathrm{C}$ sampai $120{ }^{\circ} \mathrm{C}$ atau dari $353 \mathrm{~K}$ sampai $393 \mathrm{~K}$. Kisaran konsentrasi katalis yang ditetapkan dalam persen berat DALMs mulai $0,5 \% ; 1 \%$ selanjutnya tiap kenaikan $1,5 \%$ hingga $6 \%$.

Bahan baku berupa DALMs, metanol dan katalis $\mathrm{HCl}$ dimasukkan kedalam reaktor. Suhu ditetapkan pada suhu tertentu, pengaduk dijalankan kemudian tekanan operasi dinaikkan. Setelah mencapai suhu operasi,sampel diambil selang 10 menit hingga 60 menit, selanjutnya dianalisis kadar asam lemak bebas yang terkandung pada asam lemak. 


\section{HASIL DAN PEMBAHASAN}

\section{Pengaruh suhu}

Suhu yang ditentukan pada proses ini adalah $353{ }^{\circ} \mathrm{K}, 363^{\circ} \mathrm{K}, 373{ }^{\circ} \mathrm{K}, 383^{\circ} \mathrm{K}$ dan $393^{\circ} \mathrm{K}$. Pada pengamatan ini variabel yang dibuat tetap adalah konsentrasi katalis $6 \%$ berat DALMs.

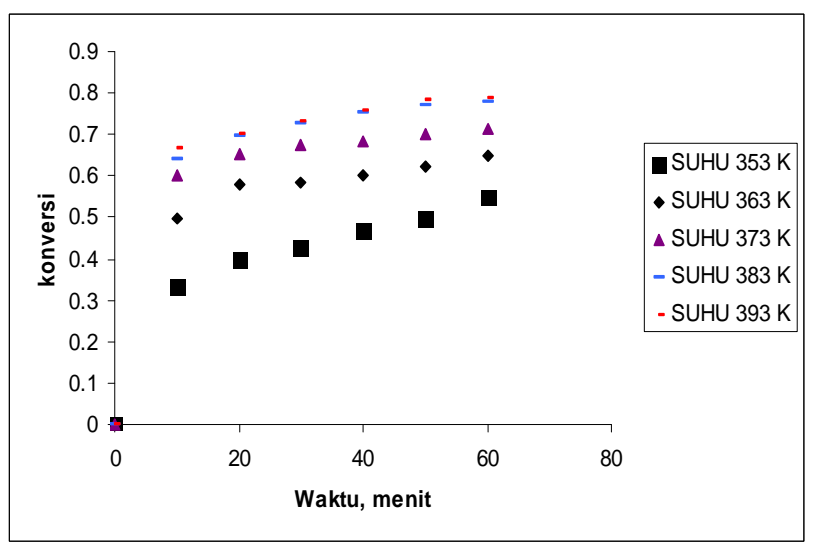

Gambar 1. Hubungan konversi reaksi dengan waktu pada variasi suhu dengan Ckat 6\% ; putaran 600 rpm; tekanan 6,5 atm.

Data hasil penelitian ditampilkan pada Gambar 1 bahwa semakin lama waktu reaksi, konversi yang diperoleh meningkat. Kondisi ini terjadi karena lamanya kontak antara molekulmolekul yang saling bertumbukan (Aziz, 2008). Konversi yang dihasilkan pada suhu 353 dan 363 $\mathrm{K}$ pada 10 menit pertama tidak lebih dari $50 \%$, kenaikan konversi cukup besar pada suhu 373 sampai 383 K. Sementara pada suhu 393 K kenaikan konversi relatif kecil ,sehingga kondisi optimum pada suhu $383 \mathrm{~K}$.

Hubungan antara konstanta kecepatan reaksi dengan kenaikan suhu dengan menggunakan persamaan Arrhenius, diperoleh hasil yang terlihat pada Gambar 2 .

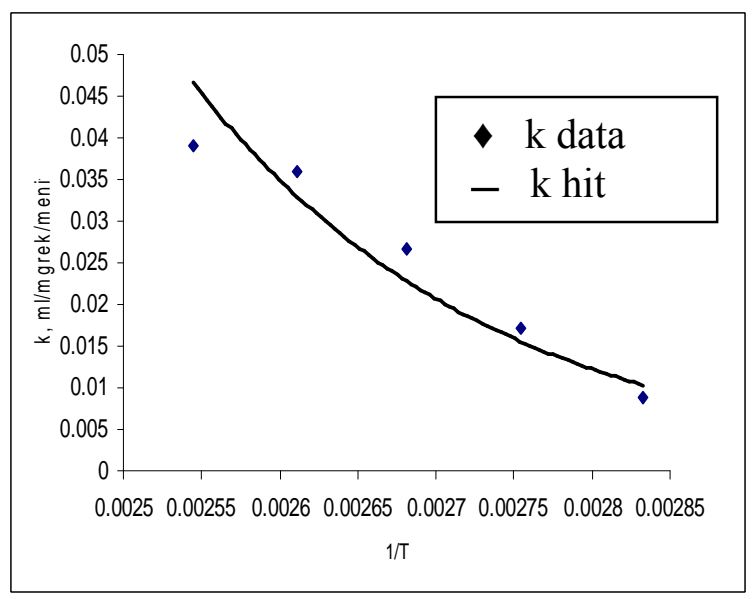

Gambar 2 . Hubungan antara 1/ T dengan (k) pada Ckat 6\% ; putaran $600 \mathrm{rpm}$; tekanan 6,5 atm.

Hubungan antara konstanta kecepatan reaksi dengan suhu, dapat diwakili persamaan Arrhenius, persamaan yang diperoleh :

$$
\mathrm{k}=28921 \operatorname{Exp}\left(\frac{-5241}{T}\right)
$$

\section{Pengaruh konsentrasi katalis}

Konsentrasi katalis divariasikan dari $0,5 \%$ ; $1,5 \% ; 3,0 \% ; 4,5 \%$ dan $6,0 \%$ terhadap berat DALMs dan suhu ditetapkan pada $383 \mathrm{~K}$. Pada Gambar 3 konversi reaksi meningkat setiap kenaikan konsentrasi katalis demikian pula dengan konstanta kecepatan reaksi.

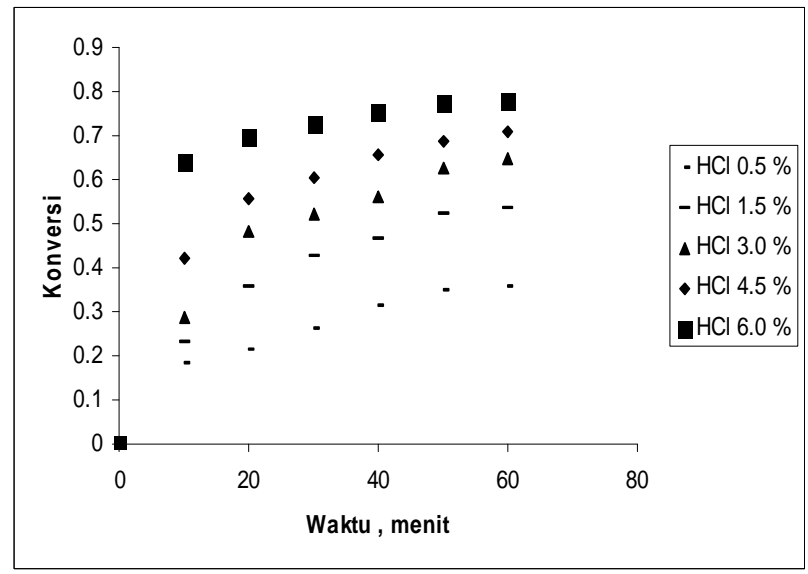

Gambar 3. Hubungan antara waktu dengan konversi pada variasi konsentrasi katalis; $\mathrm{T}=383 \mathrm{~K}$; putaran $600 \mathrm{rpm}$; tekanan 6,5 atm 
Dari Gambar 3 terlihat pengaruh konsentrasi katalis pada $0,5 \%$ kecil terhadap kenaikan konversi, sehingga konsentrasi katalis yang digunakan lebih ditingkatkan sebesar 1,5 $\%$. Setiap kenaikan konsentrasi katalis meningkatkan konversi reaksi. Kondisi optimum di peroleh pada konsentrasi $6 \%$.

Kecepatan reaksi dapat meningkat dengan penambahan katalis sehingga energi aktivasi berkurang dan jumlah molekul yang teraktifkan bertambah . Hal ini berpengaruh pula terhadap konstanta kecepatan reaksi, seperti yang ditampilkan pada Gambar 4.

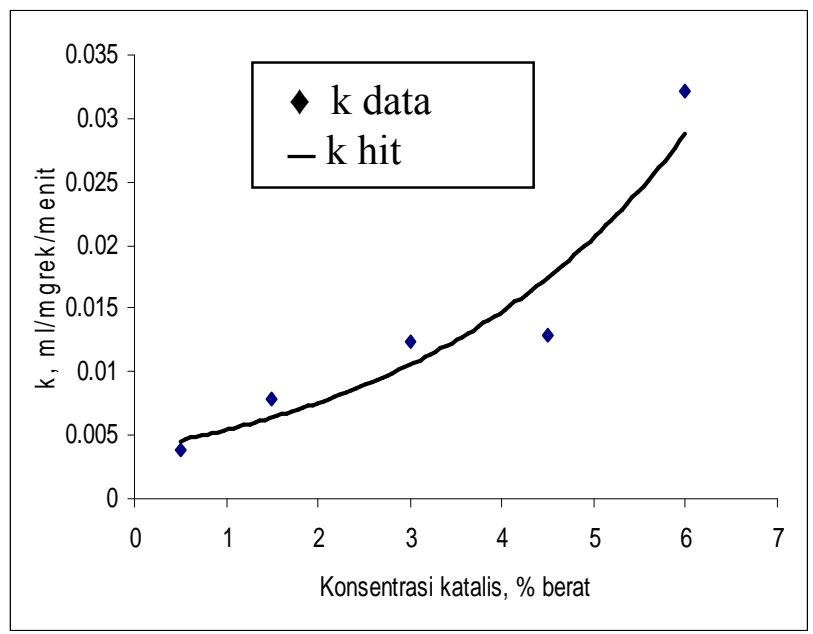

Gambar 4. Hubungan antara konsentrasi katalis dengan konstanta kecepatan reaksi dengan $\mathrm{T}=383 \mathrm{~K}$; putaran $600 \mathrm{rpm}$; tekanan 6,5 atm

Kecepatan reaksi dapat meningkat dengan penambahan katalis sehingga energi aktivasi berkurang dan jumlah molekul yang teraktifkan bertambah . Hal ini berpengaruh pula terhadap konstanta kecepatan reaksi , persamaan matematis yang menggambarkan hubungan antara konsentrasi katalis dengan konstanta kecepatan reaksi dihasilkan sebagai berikut :

$\mathrm{k}=0,0039 \operatorname{Exp}\left(0,336 \mathrm{C}_{\text {kat }}\right)$

\section{KESIMPULAN}

Konstanta kecepatan reaksi dikendalikan oleh reaksi kimia dan berorde dua terhadap asam lemak . Konversi reaksi meningkat dengan kenaikan suhu dan penambahan konsentrasi katalis , dengan menghasilkan persamaan matematis sebagai berikut:

a. Variasi suhu :

$\mathrm{k}=28921 \mathrm{EXP}\left(\frac{-5241}{T}\right)$, ralat rata-rata

yang diperoleh $3,7 \%$

b. Variasi konsentrasi katalis :

$\mathrm{k}=0,0039 \operatorname{EXP}(0,336 \mathrm{C}$ kat $)$, ralat rata-rata yang diperoleh $3,4 \%$

Kondisi optimum yang diperoleh pada perbandingan pereaksi 1 : 6 ( volum), kecepatan pengadukan $600 \mathrm{rpm}$ pada suhu $383 \mathrm{~K}$ dengan konsentrasi katalis $6 \%$ berat DALMs dan dioperasikan pada tekanan 6,5 atm.

\section{UCAPAN TERIMA KASIH}

Penulis mengucapkan terima kasih kepada seluruh dosen pada Fakultas Teknologi Industri khususnya Jurusan Teknik Kimia, Universitas Muslim Indonesia, Makassar.

\section{NOMENKLATUR}

$\mathrm{C}_{\mathrm{A}}=$ Konsentrasi asam lemak, mgrek / $\mathrm{ml}$

$\mathrm{C}_{\mathrm{AO}}=$ Konsentrasi asam lemak mula-mula , mgrek / ml

Ckat = Konsentarsi katalis ( $\%$ berat DALMs)

$\mathrm{k}=$ Kontanta kecepatan reaksi, $\mathrm{ml} /$ mgrek

/ menit

$\mathrm{N}_{\mathrm{A}} \quad=$ Jumlah ekivalen asam lemak, mgrek

$\mathrm{r}_{\mathrm{A}} \quad=$ Kecepatan reaksi, mgrek/ $\mathrm{ml} /$ menit

$\mathrm{t} \quad=$ waktu, menit.

$\mathrm{T}=$ Suhu, $\mathrm{K}$

$\mathrm{V}=$ Volume cairan dalam reaktor, $\mathrm{ml}$

$\mathrm{X}_{\mathrm{A}} \quad=$ Konversi

\section{DAFTAR PUSTAKA}

1. Aziz, I., 2008, “ Pembuatan Biodiesel dari Minyak Goreng Bekas dalam Reaktor Alir Tangki Berpengaduk", Valensi, Vol.1, No.1,

2. Bailey,A.E.1945, "Industrial oil and fat product" $.2^{\text {nd }}$ ed.pp.73. Interscience Publisher. Interscience Publisher. Inc . New York. 
3. Darnoko, D. and Cheryan, M. 2000, "Kinetic of Palm Oil Transesterfikasi in a Bath Reactor “..J. Am. Oil Chem.Soc. 77 , 1263 -1267.

4. Noureddini, H, and Zhu, D., 1997, " Kinetic of Transesterification of Soybean Oil ", J. Am.Oil Chem.Soc., 74, 1457-1463.

5. Groggins, P.H. 1958, "Technical Method Of Analysis", $2^{\text {nd }}$ ed. pp $107-110$. Mc graw Hill Book Company. Inc. New York.

6. Johnstone,R.E and Thring,M.W. 1957.'Pilot Plants,Models, and Scale Up Methods in Chemical Engineering”. pp 61- 71. Mc GrawHill Book Company .Inc. New York.

7. Kirk, R.E. and Othmer, DF.1980, "Encyclopedia of Chemical Technology". Vol 9.3 ${ }^{\text {th }}$ ed. pp. 305308, john Wiley and Sons, New York.

8. Swern, D.1982a. "Bayley's Industrial Oil and Fat Products" . vol.1, $4^{\text {th }}$ ed., John Wiley and Sons, New York. 